\title{
Bacteria can form interconnected microcolonies when a self-excreted product reduces their surface motility: evidence from individual-based model simulations
}

\author{
Nabil Mabrouk \\ INRIA, MERE Project, 2 pl. Viala, 34060 Montpellier, France \\ nabil.mabrouk@cemagref.fr
}

Phone: +33 4.73.44.07.27, Fax +33 4.73.44.06.96

Guillaume Deffuant

Cemagref, LISC, 24 avenue des Landais, 63172 Aubière Cedex, France

guillaume.deffuant@cemagref.fr

Phone: +33 4.73.44.06.14, Fax +33 4.73.44.06.96

Tim Tolker-Nielsen

Department of International Health, Immunology and Microbiology. Faculty of Health Sciences. University of Copenhagen, DK-2200 Kфbenhavn N, Denmark

Claude Lobry

INRIA, MERE Project, 2 pl. Viala, 34060 Montpellier, France

\begin{abstract}
Recent experimental observations of Pseudomonas aeruginosa, a model bacterium in biofilm research, reveal that, under specific growth conditions, bacterial cells form patterns of interconnected microcolonies. In the present work, we use an individual-based model to assess the involvement of bacteria motility and self-produced extracellular substance in the formation of these patterns. In our simulations, the pattern of interconnected microcolonies appears only when bacteria motility is reduced by excreted extracellular macromolecules. Immotile bacteria form isolated microcolonies and constantly motile bacteria form flat biofilms. Based on experimental data and computer simulations we suggest a mechanism that could be responsible for these interconnected microcolonies.
\end{abstract}




\section{Keywords}

Biofilm, Pseudomonas aeruginosa, spatial pattern, extracellular DNA

\section{Introduction}

Many bacteria have an innate propensity to form biofilms: they build structured multicellular communities attached to solid surfaces. Microscopic examination of biofilms formed by Pseudomonas aeruginosa, a model bacterium in biofilm research (Costerton et al., 1995, Davey et al., 2000), reveals a wide diversity of spatial patterns which, depending on the growth conditions, range from a flat thin layer of cells to a patchy pattern with interconnected microcolonies having complex tower or mushroom like shapes (Klausen et al., 2003b, Barken et al., 2008). At least some explanation for the different biofilm patterns formed under different conditions relates to surface motility. Conditions that promote extensive surface motility can lead to the formation of flat, homogenous biofilms, whereas biofilms characterized by aggregates result from at least a subpopulation of the community ceasing to move at an early stage of biofilm formation (Parsek and Tolker-Nielsen, 2008). In $P$. aeruginosa biofilms, formation of initial microcolonies (stalks) that subsequently become colonized by cap-forming bacteria is necessary for the formation of mushroom-shaped multicellular structures (Klausen et al., 2003a; 2003b). These multicellular structures often provide important benefits such as a higher tolerance to adverse conditions (Parsek and Tolker-Nielsen, 2008), and can be crucial in industrial processes. Therefore, much experimental and theoretical effort is currently devoted to understand their mechanisms of formation.

The formation of spatial patterns in $P$. aeruginosa biofilms involves a complex interplay between cell proliferation, surface-associated motility and the production of extracellular macromolecules that form a structural matrix (for a review see Parsek and Tolker-Nielsen (2008)). Evidence has been provided that arrest of type IV pili-mediated motility (twitching motility) plays a role in the formation of the initial microcolonies in P. aeruginosa biofilms, whereas flagelladriven motility (swarming motility) plays a role in the subsequent formation of the 
cap-portion of the mushroom-shaped structures (Klausen et al., 2003a; 2003b; Barken et al., 2008). The early stages of biofilm development by P. aeruginosa is dependent on extracellular DNA (Whitchurch et al., 2002), which is known to bind with high affinity to type IV pili (Aas et al., 2002, van Schaik et al., 2005), a fimbrae extending from the cell body and mediating surface-associated twitching motility. Hence it may be assumed that initially motile bacteria stop and form microcolonies in the regions of abundant extracellular DNA. Recently, AllesenHolm et al. (2006) visualized the spatial distribution of extracellular DNA and bacteria in $P$. aeruginosa biofilms, grown in flow chambers on minimal glucose medium. In 2-day-old biofilms the extracellular DNA was present inside the small microcolonies, but accumulated mainly in the outer layer of the microcolonies and between the microcolonies forming a grid-like structure. Zoomed views of the microcolonies revealed that they were often interconnected with thin strands of extracellular DNA covered with bacteria (see Fig. 1). In 4-day-old biofilms caplike multicellular structures had formed on top of the initial small microcolonies, and the highest concentration of extracellular DNA was present between the stalkportion and the cap-portion of the mushroom-shaped multicellular structures.
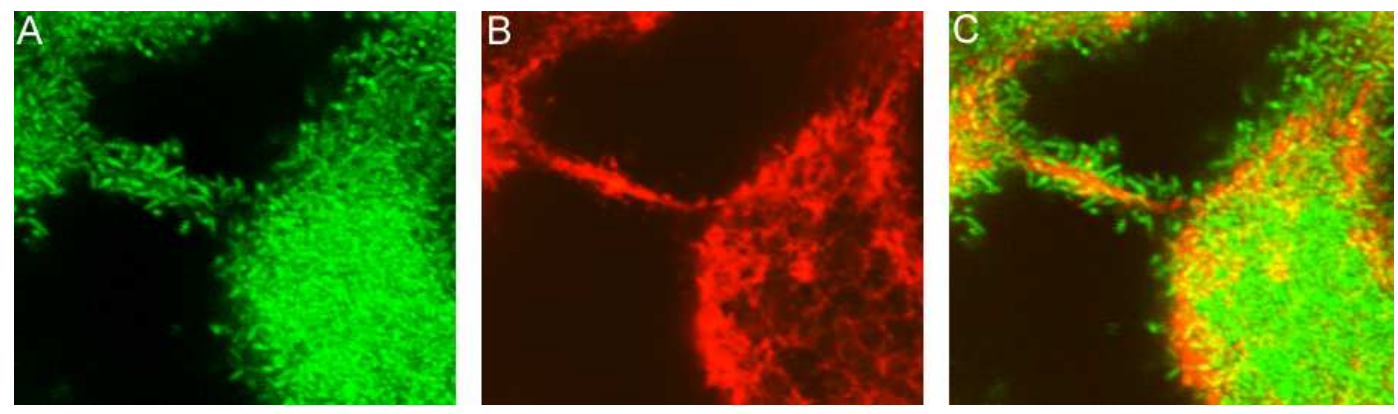

Fig. 1 Horizontal confocal laser scanning microscope section acquired in a 2-dayold DDAO-stained biofilm formed by Gfp-tagged $P$. aeruginosa PAO1. The images show the green fluorescent bacteria (A), the red fluorescent extracellular DNA (B), and an overlay of the two (C). Reproduced from Molecular Microbiology 59: 1114-1128 with permission from John Wiley \& Sons, Inc.

The factors involved when bacteria shift from being motile to sessile in biofilms are currently not fully understood. In the present article we present a simple spatially explicit individual-based model in which bacterial motility is reduced by a self-produced extracellular substance. 
Individual-based modeling is a bottom-up approach as it attempts to model a population or community by describing the actions and properties of the individuals comprising the population or the community (Grimm, 1999, Kreft et al., 2001). Spatially explicit IBMs, which include a representation of the spatial configuration of the system, allow the simulation of the spatial pattern that emerges from the interactions at the level of the individuals. IBMs are not the only bottom-up simulating approach of studying emergent spatial patterns. Cellular automaton (CA) modeling is another bottom-up approach used for simulating microcolonies patterns (Barker and Grimson, 1993) and biofilms (Wimpenny and Colasanty, 1997, Picioreanu et al., 1998a, 1998b, Hunt et al., 2003). CA models are discrete grid-based models, and differ from IBMs in that they operate on the spatial cells instead of considering the individual settled in them (Ferrer et al., 2008). Comparison of IBMs and CA models showed that differences in the simulated biofilm structure may occur for multi-species biofilms due to different approaches in redistributing the surplus biomass (van Loosdrecht et al., 2002) but that both approaches yield similar biofilm structure for a simple mono-species and mono-substrate system (van Loosdrecht et al., 2002). IBMs are however usually preferred to CA when the individual's variability need to be considered explicitly (Kreft et al., 2001, Ferrer et al., 2008).

IBMs have been widely used for modeling spatial organization of bacteria within colonies (Kreft et al., 1998, Ginovart et al., 2002) and biofilms (Kreft et al., 2001, Xavier et al., 2005) (for a review see Ferrer et al., (2008) and Hellweger and Bucci (2009)). Recently, an individual-based model of surface associated populations of $P$. aeruginosa has been presented (Picioreanu et al., 2007). The model involves a three-dimensional space and aims to provide a proof-ofprinciple of the implication of motility in the formation of biofilm structure. It reproduces qualitatively the tendency of motile bacteria to form flat biofilms and that of immotile bacteria to form microcolonies by clonal growth, and proposes detachment and reattachment processes of the motile bacteria as possible mechanisms yielding the formation of complex mushroom-shaped microcolonies. In our model, we focus on the interplay between extracellular DNA production and bacterial motility. We show that a model where bacterial migration is stopped due to adherence to self-produced extracellular DNA can produce complex patterns of interconnected microcolonies. 


\section{Methods}

We describe the model through the ODD protocol (Overview, Design concepts and Details) (Grimm et al., 2006), which was designed to facilitate descriptions of IBMs in ecology and social science (Polhill et al., 2008).

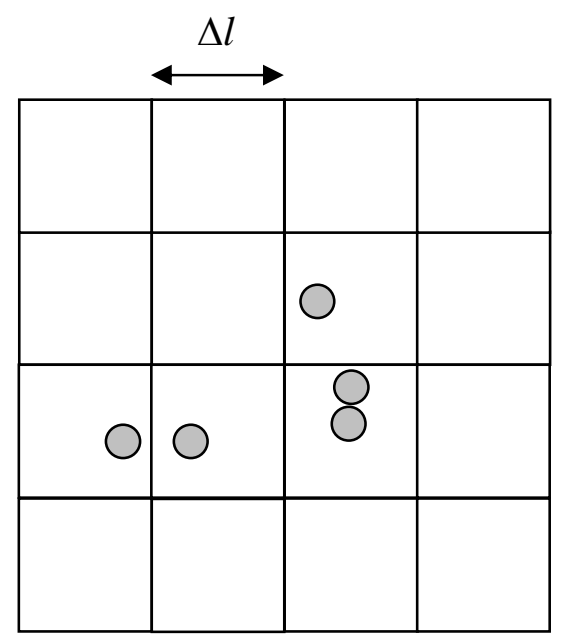

Fig. 2 Schematic representation of the model entities: bacterial cells (discs) and patches (squares with a side $\Delta l$ ). A bacterium with continuous coordinates $x, y$ is contained in the patch $i=f l o o r(x / \Delta l) j=$, floor $(y / \Delta l)$.

\section{Purpose}

The model we propose is intended to qualitatively explore the role of surfacemotility reduction by self-produced macromolecules in biofilm pattern formation. We address this question at a rather abstract level, and the model results are not compared to specific experimental results.

\section{State variables and scales}

The model is a two-dimensional representation of a biofilm system and comprises two entities: bacterial cells and their local environment (patches) (Fig. 2). Bacterial cells are represented as discs. They are characterized by the state variables: continuous position $(x, y)$, individual mass $(m)$, individual diffusion factor $\left(D_{f}\right)$ and individual substrate uptake rate $(r)($ table 1$)$. A Patch is 
characterized by the state variables: discrete position $(i, j)$, substrate concentration $(s)$, extracellular substance concentration $(p)$ and a substrate uptake rate $\left(r_{s}\right)$ corresponding to the sum of uptake rates of the individual cells contained within the patch (table 1).

\section{Scales}

We simulated the first day of the biofilm development. We discretized time with a constant time step, denoted $\Delta t=1 \mathrm{~s}$. A spatial patch has a size of $5 \times 5 \mu \mathrm{m}$ and the whole domain contains $400 \times 400$ patches (spatial domain side $l=2000 \mu \mathrm{m}$ ). Bacterial cells have variable diameters $(\sim 2 \mu \mathrm{m})$ depending on their masses.

Table 1 State variables of the individual-based model

\begin{tabular}{lll}
\hline & Variables & Description \\
\hline Bacterium state & $\begin{array}{l}\text { Continuous position of the } \\
\text { center of the bacterium }\end{array}$ & Mass \\
& $D_{f}$ & Diffusion factor \\
& $r$ & Individual substrate uptake \\
Patch state & rate \\
& Discrete position \\
& & Substrate concentration \\
& & Excreted product \\
& concentration \\
& Reaction rate (Sum of \\
& substrate uptake rates of the \\
& individual cells contained \\
& within the patch) \\
&
\end{tabular}

\section{Process overview and scheduling}

In the IBM, bacteria move stochastically along a 2-D surface while consuming substrate, growing and reproducing by binary fission and excreting a product. 
Bacteria movement is then slowed down through interactions with the excreted product yielding different patterns of microcolonies.

At each time step the following processes are performed sequentially:

- Bacteria growth: for each individual cell we (1) calculate and individual substrate uptake rate $(r)$ which depends on the mass of the cell and the local substrate concentration. (2) We use the calculated uptake rate to update the mass of the cell.

- Substrate uptake rates for patches: given the uptake rates of each individual cell, we calculate an uptake rate $\left(r_{s}\right)$ for each patch by taking the sum of the uptake rates of the individual cells contained within it.

- Division: for each individual cell we compare the cell mass to a critical value. If the cell mass is higher than the critical value than the cell is divided into two daughter cells. One of the daughter cells takes the position of the mother cell while the second is placed at random around the mother cell position at a distance $(d)$ corresponding to the diameter of the daughter cell.

- Surface motility: we model bacteria translocation as a Brownian process using an diffusion factor $\left(D_{f}\right)$ proper to each individual. For each individual cell, including newly formed cells, we calculate a diffusion factor $\left(D_{f}\right)$ using a decreasing function of the local product concentration and then move the individual cell accordingly.

- Shoving: bacteria division and motion may produce cells overlaps. In this case cells are displaced using an algorithm proposed by Kreft et al. (2001) that mimics a shoving process.

- Substrate and excreted product mass balances: we modeled the substrate and the excreted product dynamics using two diffusion-reaction equations discretized on the lattice formed by the patches. The reaction terms in these equations are calculated using the substrate uptake rate $\left(r_{s}\right)$ previously calculated for each patch.

\section{Design Concepts}

- Emergence: the IBM is designed such that the spatial pattern of bacteria and product distribution emerge from local interactions. 
- Sensing: in our model, a bacterium senses the substrate and product concentration within the patch corresponding to its position. The substrate concentration affects the growth rate of the bacterium whereas the product concentration affects the motility of the bacteria.

- Stochasticity: bacteria motility and the positioning of the daughter cells after a division event are the only stochastic processes that we considered in the IBM.

- Observation: at each time step the state variables for bacteria and patches are recorded.

\section{Submodels}

\section{Bacteria growth}

We calculate the individual substrate uptake rate $(r(t))$ of a cell located in $(x, y)$ and having a mass $m$ using the following Monod-like kinetic equation:

$$
r(t)=\mu_{\max } \cdot m \frac{s(i, j, t)}{s(i, j, t)+k_{s}}
$$

Where $s(i, j, t)$ is the substrate concentration at patch $(i, j)$ with $i=f \operatorname{loor}(x / \Delta l)$ and $j=$ floor $(y / \Delta l)$ and $\mu_{\max }$ and $k_{s}$ are Monod kinetic parameters. The growth rate of the bacterium is given by:

$$
\frac{d m}{d t}=Y_{b} \cdot r(t)
$$

Where $Y_{b}$ is the biomass yield (expressed in mass of bacteria per mass of consumed substrate). The time derivative is discretized using an Euler explicit scheme and the new mass of the cell is calculated by:

$m(t+\Delta t)=m(t)+\Delta t \cdot Y_{b} \cdot r(t)$

With $\Delta t$ the time step. The product excretion rate $r_{p}(t)$ of the considered individual cell is given by: 


$$
r_{p}(t)=Y_{p} \cdot r(t)
$$

\section{Substrate Uptake rates}

For each patch we calculate a substrate uptake rate $r_{s}(t, i, j)$ by summing the individual substrate uptake rates of the cells contained within the patch:

$$
r_{s}(t, i, j)=\frac{1}{\Delta l^{2}} \sum_{k} r_{k}(t)
$$

where $\mathrm{k}$ is the number of cells in patch $i, j$.

\section{Bacteria division}

If the mass of a focal individual (a mother cell) becomes greater than twice the initial mass of an individual $\left(m \geq 2 m_{0}\right)$ it divides into two daughter cells each with a mass $m / 2$. The first daughter cell takes the position of the mother cell while the second daughter cell is placed randomly at a distance $d$ (distance between the centers of both cells) corresponding to the diameter of the daughter cells (both daughter cells have the same diameter).

\section{Bacteria motility}

The motility of the cells is modeled as a Brownian motion process with an apparent diffusion factor $\left(D_{f}\right)$ which is specific to each individual cell. For a given bacterium located at $x, y$ at time $t$, the position of the bacterium at the instant $t+$ $\Delta t$ is given by:

$$
\begin{aligned}
& x(t+\Delta t)=x(t)+\sqrt{2 D_{f}(x, y) \Delta t} \cdot N(0,1) \\
& y(t+\Delta t)=y(t)+\sqrt{2 D_{f}(x, y) \Delta t} \cdot N(0,1)
\end{aligned}
$$

where $N(0,1)$ draws a number from a centered normal distribution of standard deviation 1 (generated using the Mersenne Twister pseudo-random number generator). As we assumed that bacteria motility was reduced by the excreted product, we calculate diffusion factor $\left(D_{f}\right)$ as a decreasing function of the excreted product concentration in the corresponding patch $(i, j)$. We use the following function: 
$D_{f}=D_{f \max } \cdot \frac{1}{1+\beta \cdot p(i, j, t)}$

where $D_{\text {fmax }}$ is the maximum diffusion factor of the bacterium, $\beta$ is a binding affinity factor and $p(i, j, t)$ is the product concentration at patch $(i, j)$. The parameter $\beta$ rules the sensitivity of $D_{f}$ to the variation of $p(i, j, t)$ as shown by figure 3.

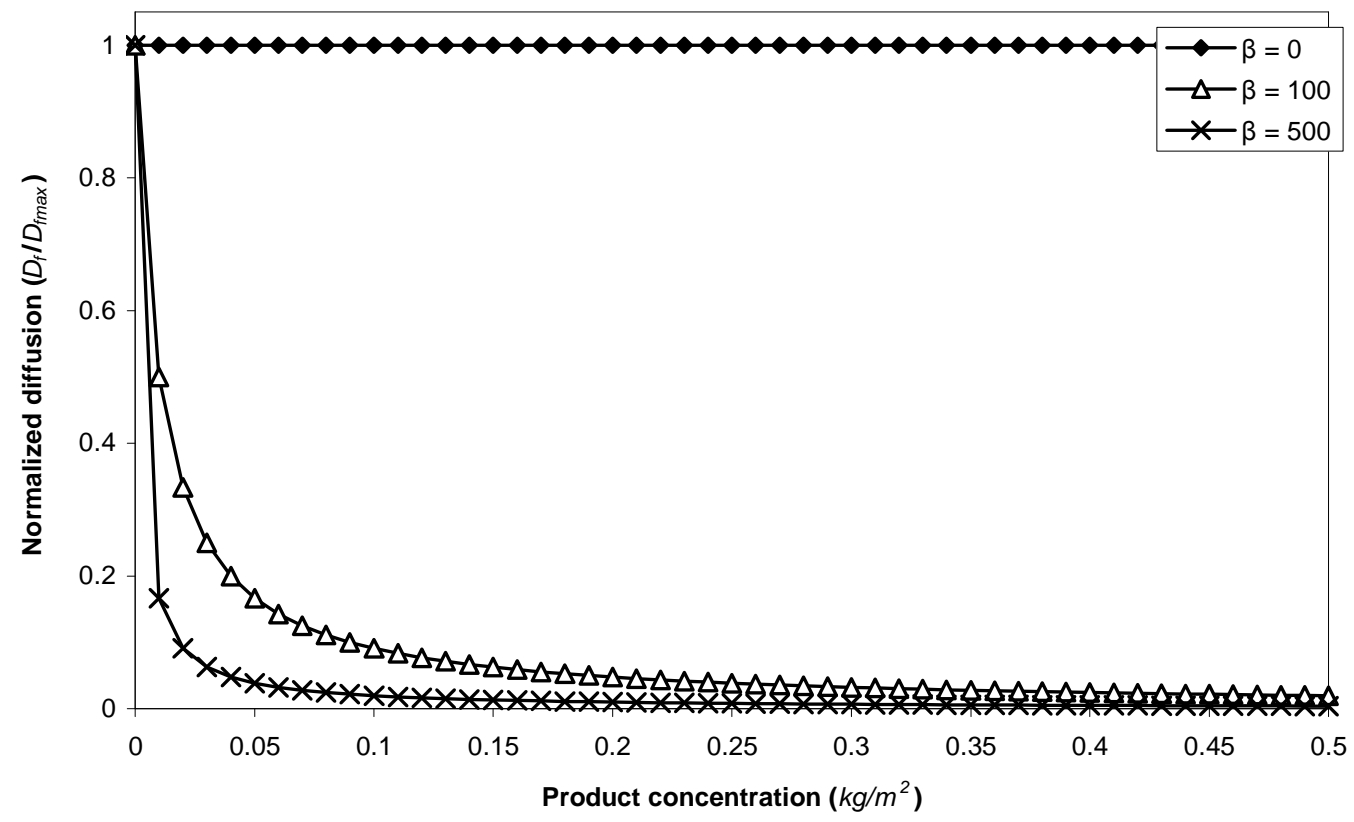

Fig. 3 Motility dependence on the excreted product concentration for different values of $\beta$

We use periodic boundary conditions for the individuals such that an individual that exits the domain from one side appears from the opposite side.

\section{Bacteria shoving}

Bacteria shove each other when they overlap. If a bacterium with radius $a$ is overlapped with $n$ neighboring cells, it is displaced with a shoving vector $\mathbf{d}$ calculated using the following equation adapted from Kreft et al. (2001):

$d=\sum_{k=1: n} \frac{a+a_{k}-d_{k}}{2} u_{k}$ 
$a_{k}$ is the radius of the neighbor cell $k, d_{k}$ is the Euclidean distance from the center of the bacterium to the center the $k^{\text {th }}$ neighboring cell and $\mathbf{u}_{\mathbf{k}}$ is a vector directed from the center of neighbor bacterium $k$ towards the center of the bacterium and having a unitary norm. We consider periodic boundary conditions for the search of overlapping neighbors and for the repositioning of the shoved individuals.

\section{Substrate and excreted product mass balance equation}

The distribution of the substrate is the solution of the following continuous diffusion-reaction equation:

$$
\frac{\partial s}{\partial t}=D_{s} \nabla^{2} s-r_{s}
$$

with periodic boundary conditions:

$$
s(t, x=0, y)=s(t, x=l, y)
$$

$$
s(t, x, y=0)=s(t, x, y=l)
$$

and having as initial conditions:

$$
s(t=0, x, y)=s_{0}
$$

The excreted product dynamic is also given by a diffusion-reaction equation:

$\frac{\partial p}{\partial t}=D_{p} \nabla^{2} p+Y_{p} r_{s}$

with periodic boundary conditions:

$$
\begin{aligned}
& p(t, x=0, y)=p(t, x=l, y) \\
& p(t, x, y=0)=p(t, x, y=l)
\end{aligned}
$$

and having as initial conditions

$$
p(t=0, x, y)=0
$$

$Y_{p}$ in (eq. 13) is the product yield expressed in mass of excreted product per mass of consumed substrate. We discretize the substrate and the product mass balance equations with respect to space on the lattice formed with the patches using a four-point scheme. The reaction term has already been calculated for each patch (eq. 5). We discretize the time derivative term in the substrate and the product mass balance equations using an implicit scheme for the diffusion term. Note that 
the reaction term is calculated on the basis of an explicit scheme. The obtained discretized system is a sparse linear system that we solve using the conjugate gradient method (Hestenes and Stiefel, 1952). This gives the new substrate and product concentrations in each patch.

\section{IBM parameters}

Unless explicitly specified, we use the parameters values in table 2 for the individual-based model.

Table 2 Individual-based model parameters. (*): assumed, (**): adapted from [30], (***) adapted from [22]

\begin{tabular}{llll}
\hline Parameter & Description & Units & Value \\
\hline$l$ & Domain side & $\mu \mathrm{m}$ & $2000^{(*)}$ \\
$\Delta l$ & Spatial step & $\mu \mathrm{m}$ & $5^{(*)}$ \\
$D_{s}$ & Substrate diffusion constant & $\mathrm{m}^{2} / \mathrm{s}$ & $10^{-10(* *)}$ \\
$D_{p}$ & Product diffusion constant & $\mathrm{m}^{2} / \mathrm{s}$ & $10^{-16(*)}$ \\
$D_{f m a x}$ & Maximum diffusion factor & $\mathrm{m}^{2} / \mathrm{s}$ & $10^{-12(*)}$ \\
$\mu_{m a x}$ & for the bacteria & & \\
$k_{s}$ & Maximum growth rate & $\mathrm{kg}_{\text {substrate }} /\left(\mathrm{kg}_{\text {biomass }} \mathrm{s}\right)$ & $10^{-4(* *)}$ \\
$Y_{p}$ & Affinity constant & $\mathrm{kg}_{\text {substrate }} / \mathrm{m}^{2}$ & $0.01^{(* *)}$ \\
$Y_{b}$ & Product yield & $\left(\mathrm{kg}_{\text {product }} / \mathrm{kg}_{\text {substrate }}\right)$ & $0.1^{(*)}$ \\
$\rho_{b}$ & Biomass yield & $\left(\mathrm{kg}_{\text {biomass }} / \mathrm{kg}_{\text {substrate }}\right)$ & $0.9^{(*)}$ \\
$\beta$ & Density of a bacterial cell & $\left(\mathrm{kg}_{\text {biomass }} / \mathrm{m}^{2}\right)$ & $29010^{-6(* *)}$ \\
\hline
\end{tabular}

\section{Initialization}

We initialize all simulations with:

- a uniform initial substrate concentration $s_{0}$

- a uniformly null concentration of excreted product

- $N_{0}$ bacterial cells drawn at random in the domain each with the same initial mass $m_{0}$

Initial conditions are detailed in table 3. 
Table 3 Initial conditions of the individual-based model

\begin{tabular}{llll}
\hline Parameter & Description & Units & Value \\
\hline$s_{0}$ & Initial substrate concentration in all patches & $\mathrm{kg} / \mathrm{m}^{2}$ & 10.0 \\
$p_{0}$ & Initial product concentration in all patches & $\mathrm{kg} / \mathrm{m}^{2}$ & 0.0 \\
$N_{0}$ & Initial number of bacterial cells & $\#$ & 100 \\
$m_{0}$ & Initial mass of a bacterium & $\mathrm{kg}$ & $10^{-15}$
\end{tabular}

\section{Model implementation}

We implemented the model using the Java programming language and the Mason framework. Mason is a discrete event multiagent simulation library code developed at the George Mason University for implementing multi-agent models (Luke et al., 2004).

\section{Results}

We simulate the patterns formed by the spatial distribution of bacteria and the excreted product displayed after 9 and 18 hours for different values of $\beta$ (the parameter determining the impact of the excreted product on bacteria motility) and for the case of immotile bacteria. Two extreme cases can be identified. In the first case, bacteria are motile and their motility is independent from the excreted product $(\beta=0)$ while in the second case bacteria are immotile $D_{f \max }=0$. Figures 4 and 5 show the patterns obtained in these limiting cases. Motile cells disperse over the spatial domain (Fig. 4) in contrast with immotile cells that form isolated microcolonies (Fig. 5). These results are consistent with previous theoretical (Picioreanu et al., 2007) and experimental (Klausen et al., 2003b) studies of $P$. aeruginosa showing that motile cells tend to form flat biofilms while immotile bacteria form round shaped microcolonies. 

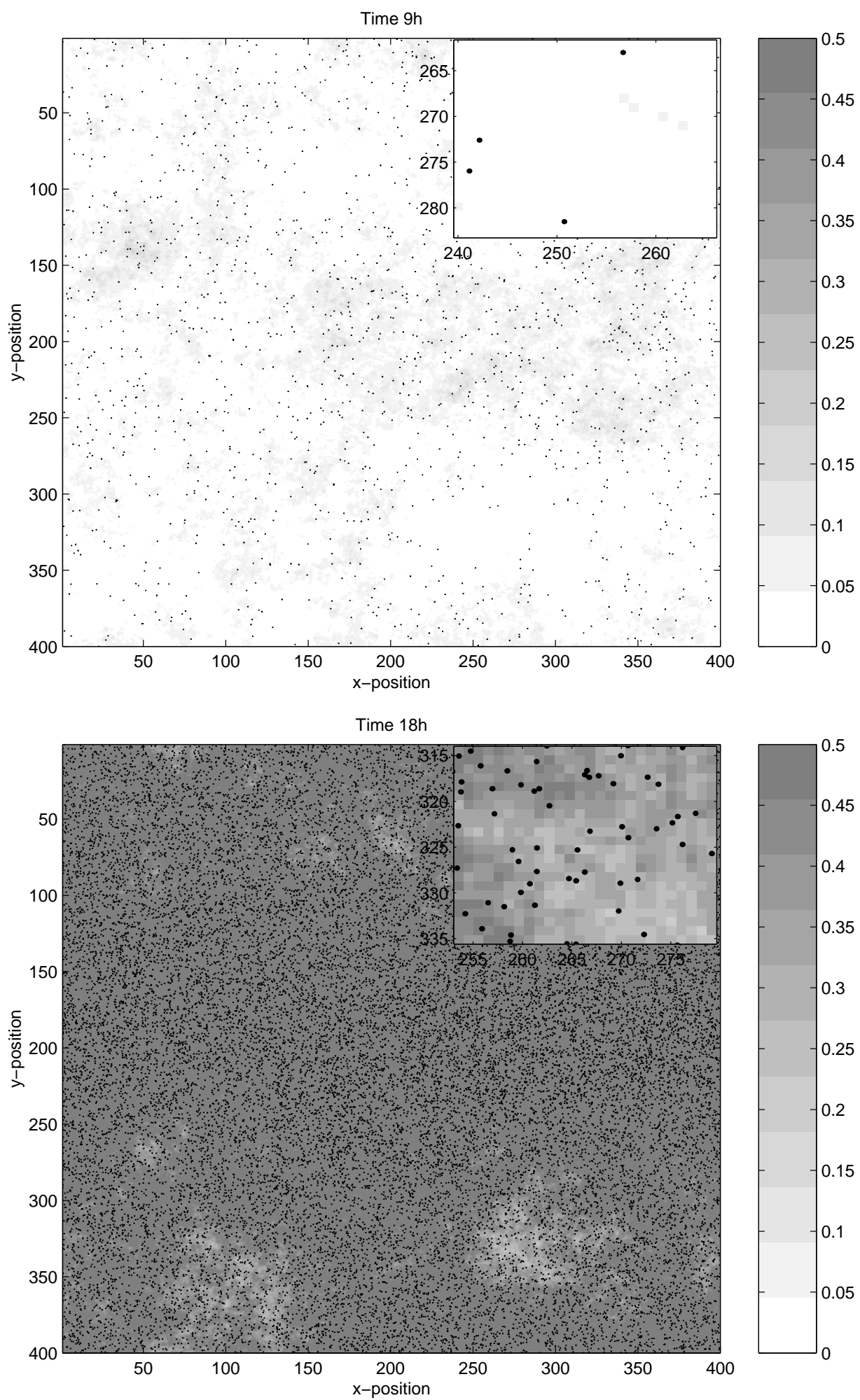

Fig. 4 Overall and zoomed view of the spatial pattern formed by the bacteria (black dots) and the excreted macromolecules (gray scale) for motile bacteria for $\beta=0$ at time 9 and 18 hours 
We also simulated intermediate cases where the bacteria motility depends on the local concentration of the excreted product. Figure 6 and 7 show examples of spatial pattern obtained after 9 and 18 hours for a small and a large value of the parameter $\beta$ respectively. As the system evolves over time, the patterns of microcolony formation under the two parameterizations begin to diverge. A large value of $\beta$ results in microcolonies that are more spatially discrete with higher densities of individuals within them (Figure 7), while the smaller value of $\beta$ results in a pattern of microcolonies that are more amorphous in size and shape, are more connected with each other, and densities of bacteria within them are lower (Figure 6).

In our simulations, microcolony formation is initiated by the local accumulation of the product excreted by the cells along their Brownian trajectories. The product excretion rate is maximal ( $\sim Y_{p} \mu_{\max }$, see Equations 1 and 6$)$ at the beginning of the simulation when the substrate $\left(S>>k_{s}\right.$ in Equation 1) is abundant and accumulates due to its low diffusion factor. For large values of $\beta$ bacteria are rapidly entrapped within the locations containing the excreted product and their daughter cells tend to accumulate locally yielding dense and discrete microcolonies. In the opposite for small values of $\beta$, bacteria and their daughter cells tend to disperse and the yielded microcolonies have amorphous shape. Analogously, simulation with different values of the product excretion ratio $Y_{p}$ (Equation 6), at a constant value of $\beta$, between the two extreme cases of $Y_{p}=0$ (no product excretion) and $Y_{p}=1.0$ (no growth, all the substrate is released back on the form of product) yields patterns that vary respectively from uniform distribution of the bacteria to the formation of isolated, round-shaped microcolonies (data not shown). This suggests that the binding affinity factor $(\beta)$ and the product excretion rate may have a significant impact on the patterns of spatial distribution of the bacteria. In our model, the substrate concentration impacts the rate of product excretion. An initial low substrate level yields low rates of product excretion of the individuals which may not be sufficient to reduce the motility of the bacteria and the formation of microcolonies. In our simulation the initial substrate level is relatively high and only $90 \%$ of this initial stock is consumed by the end of the simulation. 

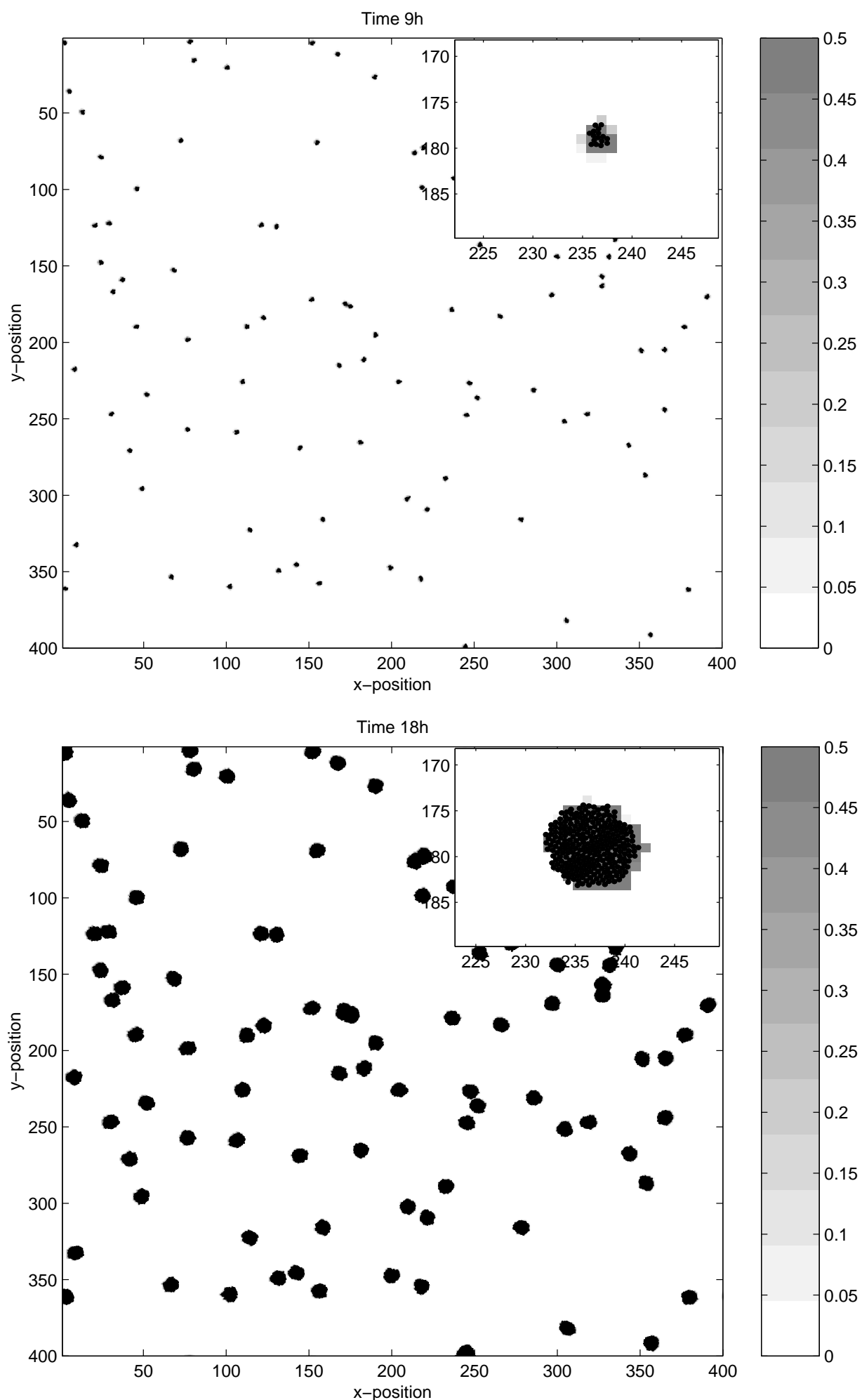

Fig. 5 Overall and zoomed view of the spatial pattern formed by the bacteria (black dots) and the excreted macromolecules (gray scale) for immotile bacteria at time 9 and 18 hours 

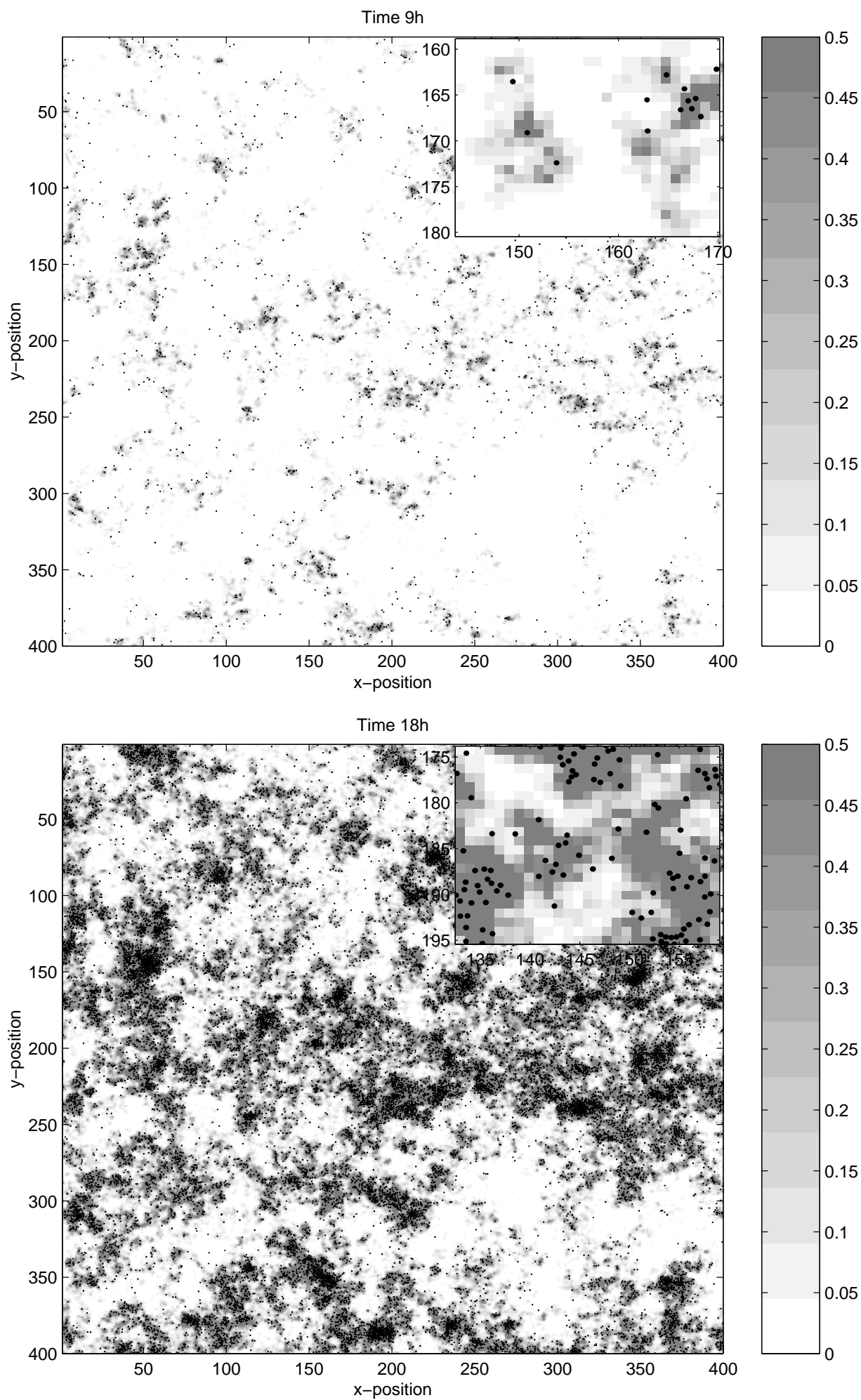

Fig. 6 Overall and zoomed view of the spatial pattern formed by the bacteria (black dots) and the excreted macromolecules (gray scale) for motile bacteria for $\beta=100$ at time 9 and 18 hours 

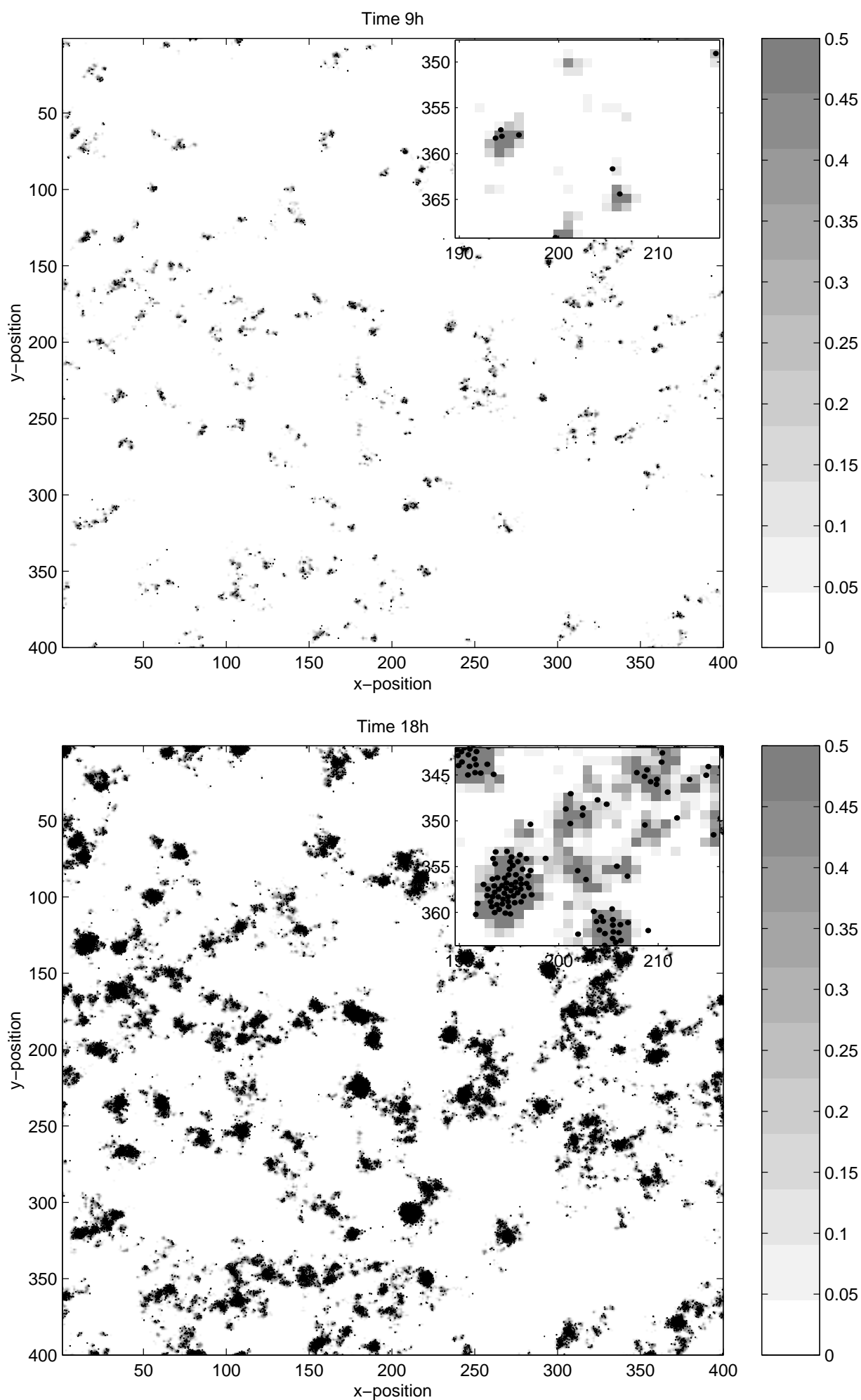

Fig. 7 Overall and zoomed view of the spatial pattern formed by the bacteria (black dots) and the excreted macromolecules (gray scale) for motile bacteria for $\beta=500$ at time 9 and 18 hours

We investigate how the interconnections between the microcolonies form in the case of large value of binding affinity parameter $(\beta=500)$. Figure 8 shows a 
zoomed view of the formation of the interconnection between two neighboring microcolonies.
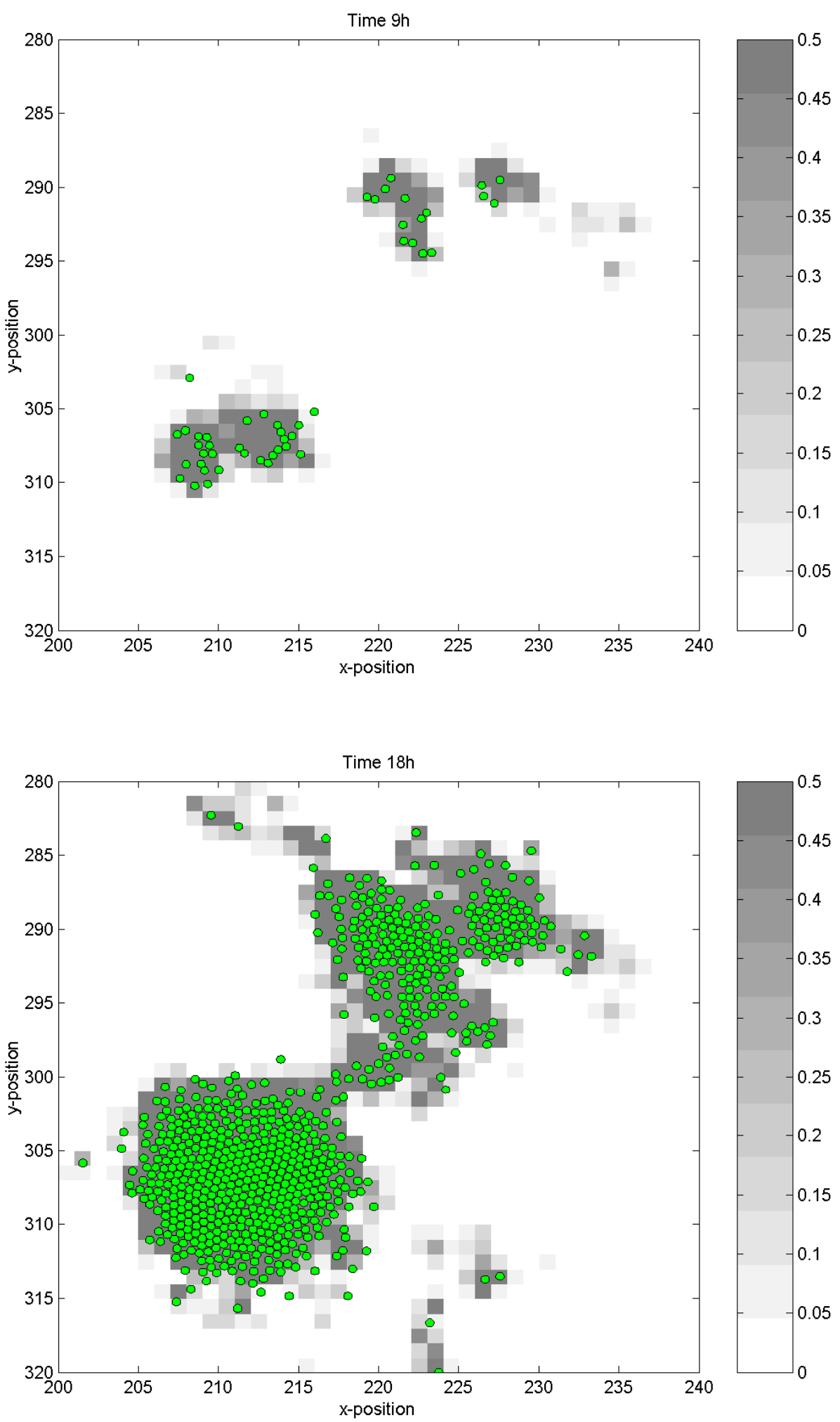

Fig. 8 Zoomed view of interconnection formation between two microcolonies for a binding affinity $\beta=500$ at time 9 and 18 hours. Bacteria are represented with green dots and the excreted product concentration with gray scale. 
The interconnection seems to be created by bacteria which go from a microcolony to a neighboring one, and which progressively accumulate excreted product on the path. The resultant pattern is formed with dense and discrete microcolonies interconnected with relatively thin strands of bacteria and excreted product.

\section{Discussion}

In this work we abstract experimental observations on $P$. aeruginosa biofilm development (Whitchurch et al., 2002, Klausen et al., 2003a; 2003b; AllesenHolm et al., 2006; Barken et al., 2008) in an individual-based model and investigate how bacteria motility reduction due to a self-produced substance yields different spatial patterns during the early stages of biofilm development. Our simulation results suggest that self-produced substance-mediated motility reduction does play a role in microcolony formation. Furthermore, in some cases, these simulated microcolonies build interconnections, similar to interconnected microcolonies observed during the early stages of $P$. aeruginosa biofilm development in flow chambers (Allesen-Holm et al., 2006), and also in biofilms formed by Pseudomonas species in marine environments (Dalton et al., 1994, Dalton et al., 1996).

Several authors already explored the mechanisms yielding microcolonies in biofilms (Alpkvist et al., 2006, Picioreanu et al., 2007). However, the pattern of interconnected microcolonies cannot be obtained with these usual mechanisms: immotile bacteria form isolated microcolonies and constantly motile bacteria form flat biofilms. Based on experimental data and computer simulations we suggest a mechanism that could be responsible for the observed patterns. Our model shows that microcolonies may result from bacteria motility reduction by self-produced macromolecules. The analysis of the simulation results suggests that cells on the edge of a microcolony occasionally detach and undergo a surface-associated motility until being captured by a neighboring microcolony. The path of the migrating cell is marked by the excreted macromolecules and is progressively reinforced by other migrating cells. This results in the formation of an interconnection between the neighboring microcolonies. However, more investigation is necessary to strengthen or falsify this hypothesis.

This investigation could be important for a better understanding of biofilm functions. Indeed, it is well accepted that the presence of different subpopulations 
in microcolonies can favor the survival of one or more subpopulations under adverse conditions (Parsek and Tolker-Nielsen, 2008, Johnson, 2008). However, recent observations suggest that in some cases the matrix of extracellular DNA (and possibly other products) may guide migration of the cells between microcolonies ( $\mathrm{Lu}$ et al., 2005, Barken et al., 2008) favoring a type of collaboration between distinct subpopulations within a biofilm. This may be related to studies in landscape ecology where this pattern of interconnected habitats is recognized as particularly important (Burel and Baudry, 2003).

Individual-based models are appealing to microbiologists because of the emphasis on the individual cell as the fundamental unit and the richness of their dynamic. However when they are too complex they often become difficult to analyze which limits their practical payoff (Grimm and Railsback, 2005). Therefore, we have attempted to keep our model as simple as possible and inspired by the phenomenological results mentioned in the introduction, but rich enough to produce patterns of interconnected microcolonies. Johnson (2008) proposed a model based on the assumption of the "direct" interaction between individual cells through attractive (and repulsive) forces arguing that forces between cells can be a proxy for the behavior we expect to see due to chemotaxis in response to chemicals released by other cells (Johnson, 2008). The assumption simplifies the model as the dynamic of the excreted product is not considered explicitly. This is a reasonable assumption when the dynamics of the chemical being produced is fast (high diffusion) compared to the dynamic of the bacteria (motility and growth) (Lee et al., 2001). Our model is based on the assumption that the excreted macromolecules like DNA and exopolymers diffuse at low rates and persist on the path of the motile bacteria. This seems to play a role in the formation of the interconnected microcolonies as microcolonies yielded by Johnson's model through attractive/repulsive forces seem not to be interconnected (Johnson, 2008). Our study included, however, some limitations that should be acknowledged for future research in this area. Examples, inherent to individual-based modeling approach, include the question of how to measure the "goodness" of an IBM. Grimm and Railsback (2005) suggested that testing an IBM against multiple observed patterns is a powerful way to assess the IBM capacity to capture system's essential characteristics. In this work we assessed the "goodness" of our IBM through comparison of an observed pattern (connected microcolonies in 
fig.1) to a simulated one (fig.8). Despite the similarities between the experimental and simulated patterns (thin path of bacteria and product connecting neighboring microcolonies) there are still differences. For example cells surrounded the thin path in figure 1 while they are contained in the area with high amount of product in figure 8. Therefore, additional patterns should be identified and compared to the simulated ones in order to strengthen or falsify the hypothetical implication of self-excreted product in motility reduction and formation of interconnected microcolonies. Another limitation of our model is the determination of parameters like the binding affinity factor $(\beta)$ and cell diffusion $\left(D_{f}\right)$. These parameters may be difficult to obtain from experimental observations and their impact should be assessed through sensitivity analysis.

Finally, our work can be extended beyond its basic premise and valuable research remains to be conducted. For instance the model can be extended to investigate the effect of other macromolecules like exopolymers on the bacteria motility and microcolonies formation. Another potential extension is to include additional processes like bacteria detachment and substrate feeding which allow investigating the effect of the interactions between cell motility and excreted macromolecules on the architecture of mature biofilms.

\section{Acknowledgements}

The research was partly supported by Patres Project (NEST 043264).

\section{References}

1. Aas, F.E., Wolfgang, M., Frye, S., Dunham, S., Lvold, C., Koomey, M.: Competence for natural transformation in Neisseria gonorrhoea: components of DNA binding and uptake linked to type IV pilus expression. Molecular Microbiology 46 (2002) 749-760

2. Allesen-Holm, M., Barken, K.B., Yang, L., Klausen, M., Webb, J.S., Kjelleberg, S., Molin,S., Givskov, M., Tolker-Nielsen, T.: A characterization of DNA release in Pseudomonas aeruginosa cultures and biofilms. Molecular Microbiology 59 (2006) 1114-1128

3. Alpkvist, E., Picioreanu, C., van Loosdrecht, M.C., Heyden, A.: Three-dimensional biofilm model with individual cells and continuum EPS matrix. Biotechnology and Bioengineering 94 (2006) 961-979 
4. Barken, K.B., Pamp, S.J., Yang, L., Gjermansen, M., Bertrand, J.J., Klausen, M., Givskov, M., Whitchurch, C.B., Engel, J.N., Tolker-Nielsen, T.: Roles of type IV pili, flagellum mediated motility and extracellular DNA in the formation of mature multicellular structures in Pseudomonas aeruginosa biofilms. Environmental Microbiology 10 (2008) 2331-2343

5. Barker, G. C., Grimson, M. J.: A cellular automaton model of microbial growth. Binary 5 (1993) 132-137

6. Burel, F., Baudry, J.: Landscape Ecology. (2003)

7. Costerton, J., Lewandowski, Z., Caldwell, D., Korber, D., Lappin-Scott, H.: Microbial biofilms. Annu Rev Microbiol 49 (1995) 711-745

8. Dalton, H.M., Goodman, A.E., Marshall, K.C.: Diversity in surface colonization behavior in marine bacteria. Journal of Industrial Microbiology and Biotechnology 17 (1996) 228-234

9. Dalton, H.M., Poulsen, L., Halaz, P., Angles, M., Goodman, A.: Substratum-induced morphological changes in a marine bacterium and their relevance to biofilm structure. Journal of Bacteriology 176 (1994) 6900-6906

10. Davey, M.E., O'Toole, G.A.: Microbial biofilms: from ecology to molecular genetics. Microbiology and Molecular Biology Reviews 12 (2000) 847-867

11. Ferrer, J., Prats, C., Lopez, D.:Individual-based Modelling: An Essential Tool for Microbiology. Journal of Biological Physics 34 (2008) 19-37

12. Ginovart, M., Lopez, D., Valls, J., Silbert, M.: Individual-based simulations of bacterial growth on agar plates. Physica A 305 (2002) 604-618

13. Grimm, V.: Ten years of individual-based modelling in ecology: what have we learned and what could we learn in the future? Ecological Modelling 115 (1999) 129-148

14. Grimm, V., Berger, U., Bastiansen, F., Eliassen, S., Ginot, V., Giske, J., Goss-Custard, J., Grand, T., Heinz, S.K., Huse, G., Huth, A., Jepsen, J.U., Jorgensen, C., Mooij, W.M., Muller, B., Pe'er, G., Piou, C., Railsback, S.F., Robbins, A.M., Robbins, M.M., Rossmanith, E., Ruger, N., Strand, E., Souissi, S., Stillman, R.A., Vabo, R., Visser, U., DeAngelis, D.L.: A standard protocol for describing individual-based and agent-based models. Ecological Modelling 198 (2006) 115126 
15. Grimm, V., Railsback, S.F.: Individual-based Modeling and Ecology. Princeton University Press (2005)

16. Hellweger, F.L., Bucci, V.: A bunch of tiny individuals: individual-based modeling for microbes. Ecological Modelling 220 (2009) 8-22

17. Hestenes, M., R. and Stiefel, E.: Methods of conjugate gradients for solving linear systems. Journal of Research of the National Bureau of Standards 46 (1952)409-436

18. Hunt, S.M., Hamilton, M.A., Sears, J.T., Harkin, G., Reno, J.: A computer investigation of chemically mediated detachment in bacterial biofilms. Microbiology 149 (2003) 1155-1163

19. Johnson, L.R.: Microcolony and biofilm formation as a survival strategy for bacteria. Journal of Theoretical Biology 251 (2008) 24-34

20. Klausen, M., Heydorn, A., Ragas, P., Lambertsen, L., Aaes-Jørgensen, A., Molin, S. and Tolker-Nielsen, T.: Biofilm formation by Pseudomonas aeruginosa wild type, flagella and type IV pili mutants. Molecular Microbiology 48 (2003a) 1511-1524.

21. Klausen, M., Aaes-Jorgensen, A., Molin, S., Tolker-Nielsen, T.: Involvement of bacterial migration in the development of complex multicellular structures in Pseudomonas aeruginosa biofilms. Molecular Microbiology 50 (2003b) 61-68

22. Kreft, J.U., Booth, G., Wimpenny, J.W.: Bacsim, a simulator for individual-based modeling of bacterial colony growth. Microbiology 144 (1998) 3275-3278

23. Kreft, J.U., Picioreanu, C., Wimpenny, J.W., van Loosdrecht, M.C.: Individual-based modelling of biofilms. Microbiology 147 (2001) 2897-2912

24. Lee, C., Hoopes, M., Diehl, J. Gilliland, W., Huxel, G. Leaver, E., McCann, K., Umbanhowar, J., Mogilner, A.: Non-local concepts and models in biology. Journal of Theoretical Biology 210 (2001) 201-219

25. Luke, S., Cioffi-Revilla, C., Panait, L., Sullivan, K.: Mason : A Java multi-agent simulation toolkit. Proceedings of the SwarmFest Workshop (2004)

26. Lu, A., Cho, K., Black, W.P., Duan, X.y., Lux, R., Yang, Z., Kaplan, H.B., Zusman, D.R., Shi,W.: Exopolysaccharide biosynthesis genes required for social motility in Myxococcus xanthus. Molecular Microbiology 55 (2005) 206-220 
27. Parsek, M.R., Tolker-Nielsen, T.: Pattern formation in Pseudomonas aeruginosa biofilms. Current Opinion in Microbiology 11 (2008) 560-566

28. Picioreanu, C., van Loosdrecht, M. C. M. \& Heijnen, J. J.: A new combined differential-discrete cellular automaton approach for bioolm modeling: application for growth in gel beads. Biotech Bioeng 57 (1998a) 718-731

29. Picioreanu, C., van Loosdrecht, M.C.M., Heijnen, J.J.: Mathematical modeling of biofilm structure with a hybrid differential-discrete cellular automaton. Biotech Bioeng 58 (1998b) 101116

30. Picioreanu, C., Kreft, J.U., Klaussen, M., Haagensen, J.A.J, Tolker-Nielson,T., Molin, S.: Microbial mobility involvement in biofilm structure formation - a $3 \mathrm{~d}$ modelling study. Water Science \& Technology 55 (2007) 337-343

31. Polhill, J.G., Parker, D., Brown, D., Grimm, V.: Using the ODD protocol for describing three agent-based social simulation models of land-use change. Journal of Artificial Societies and Social Simulation 11 (2008) 3

32. van Loosdrecht, M.C.M., Heijnen, J.J., Eberl, H., Kreft,J., Picioreanu, C.: Mathematical modelling of biofilm structures. Antonie van Leeuwenhoek 81 (2002) 245-256

33. van Schaik, E.J., Giltner, C.L., Audette, G.F., Keizer, D.W., Bautista, D.L., Slupsky, C.M., Sykes, B.D., Irvin, R.T.: DNA binding: a novel function of Pseudomonas aeruginosa type IV pili. J. Bacteriol. 187 (2005) 1455-1464

34. Whitchurch, C., Tolker-Nielsen, T., Ragas, P.C., Mattick, J.S.: Extracellular DNA required for bacterial biofilm formation. Science 295 (2002) 1487-1487

35. Wimpenny, J.W.T., Colasanti, R.: A unifying hypothesis for the structure of microbial biofilms based on cellular automaton models. FEMS Microb Ecol 22 (1997) 1-16

36. Xavier, J.B., Picioreanu, C., van Loosdrecht, M.C.M.: A framework for multidimensional modeling of activity and structure of multispecies biofilms. Environmental Microbiology 7 (2005) 1085-1103 
